\title{
Das Durchdrückjahr
}

\section{Erhard Taverna}

Dr. med., Mitglied der Redaktion

Die Vorgeschichte ist bekannt: Die alten Eidgenossen hatten den Käse, die Freiheit und Neutralität, das Bankgeheimnis und die Demokratie erfunden. Die siegreichen Schlachten machten sie reif, wehrhaft, bescheiden und gerecht, und die Heldentaten der Vorfahren sicherten ihnen eine Sonderstellung unter den Völkern. Wer so viele Erfolge vorweist, wird nicht von Kritik verschont. Friedrich Engels beschrieb die Einwohner «als breit von Schultern mit wenig Gehirn, aber viel Wade», Friedrich Dürrenmatt sah sich in einem grossen Gefängnis, Max Frisch entdeckte ein kleines Herrenvolk in Gefahr, Thomas Meyer schrieb über die heimliche Gier des Wählers und Lukas Bärfuss geisselte den Wahnsinn des Alpenlandes. Eine neue Historikergeneration demontierte liebgewordene Mythen. Sogar Peter Bichsel konnte sich einfach nicht mehr vorstellen, "dass die alten Eidgenossen idealere Gestalten waren als mein Nachbar und ich». Umzingelt von einem friedlichen Europa geriet die Willensnation in eine tiefe Krise, die bekanntlich in der Feststellung «La Suisse n'existe pas» ihren Tiefpunkt erreichte. Ungelöste Probleme wie Zersiede-

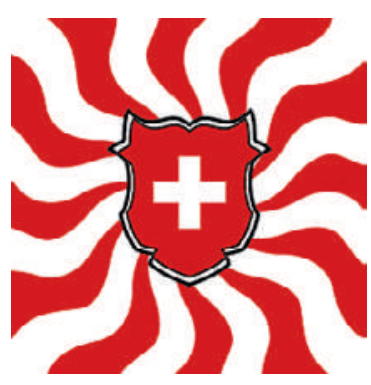

nung. Dank der geforderten Landesverweisungen und Einreiseverbote von fünf bis fünfzehn Jahren schrumpften die Agglomerationen auf die Hälfte, die Stauzeiten und Unfälle gingen merklich zurück, die Luft wurde sauberer, Bodenspekulanten liessen sich umschulen und die Menschen verhielten sich allgemein friedlicher. Die Gegner dieser zweiten Aktion, auch als Ergänzungsinitiative bekannt, hatten sich gründlich geirrt. Entgegen ihren Befürchtungen wurden des Landes verwiesene Schweizer und Schweizerinnen in allen entwickelten Ländern mit offenen Armen aufgenommen, sind sie doch bis heute sauber und beliebt, gut ausgebildet und dank Frühenglisch bestens auf eine neue Existenz vorbereitet. Junge Erwachsene, wie Krawallmacher, Sprayer, lung, Dichtestress, Einwanderung und Energiewende verunsicherten die Wählerschaft. Doch: «Wo aber die Gefahr am grössten ist, wächst das Rettende auch», hatte schon Friedrich Hölderlin erkannt.

Das Unbehagen wurde erfolgreich bewirtschaftet, und die Rettung nahte in der Gestalt einer Volkspartei, die ausschaffen wollte, was sie als soziales Übel zu erkennen glaubte. Es war der überfremdende, weniger profitable, die Abfallordnung missachtende Bevölkerungsteil, auf den die zu ändernde Bundesverfassung zielte. Unabhängig von politischen Auffassungen sind sich heute alle Fachleute einig, dass die Abstimmung über die Durchdrückungsinitiative Geschichte schrieb [1]. Denn eine Ergänzungsinitiative hatte kurz danach, mit einem überwältigenden Mehr angenommen, erreicht, dass die geplanten Bestimmungen auf die ganze Wohnbevölkerung ausgedehnt wurden. Jahrzehnte später eröffnet sich ein faszinierender Rückblick auf die Folgen einer genialen Strategie, die viele scheinbar unlösbare Probleme löste. Alles was da aufgelistet war, wie Einbrüche, Sachbeschädigungen, Hausfriedensbruch, Wucher und Drohungen gegen Behörden und Beamte, wurde nun, unbesehen der Herkunft von Täter und Täterinnen, zu einem effizienten Mittel einer nachhaltigen Landespla-
Kiffer und Kokser, waren als moderne Reisläufer in allen Konfliktzonen unverzichtbar. Diese flächendeckende Entsorgung verwandelte Schlagstöcke und Tränengas in museale Gegenstände. Auch entkam damit das Land unverhofft der Wachstumsfalle, was in zahlreichen Ländern zu ähnlichen Massnahmen führte. Ein entlastetes Gesundheitswesen konnte sich ungestört auf die ausländische, zahlungskräftige Klientel konzentrieren. Weil bekanntlich viele Mediziner freiwillig in die Emirate auswanderten, sah sich das Parlament gezwungen, einen befristeten Ausreisestopp zu verfügen. Die getroffenen Gerichtsentscheide hatten natürlich Auswirkungen auf die verbleibende Bevölkerung. Dank dramatisch gesunkenen Kriminalitätsraten wurden leere Gefängnisse umfunktioniert und Polizeikorps drastisch verkleinert. Wer heute nicht Kühe hütet oder in der Altenpflege tätig ist, arbeitet für Greenpeace. Das Land versorgt sich inzwischen selber und bei Begriffen wie Delikte und Ausländer denkt der Einheimische an Xenophyten, Tigermücken und ähnliches Geschmeiss. Mit dem Verschwinden der kriminellen Restenergien hat leider eine gewisse Trägheit um sich gegriffen. Fussballklubs spielen nur noch in der untersten Liga. Der Sensationspresse gehen die Themen aus. Das Inselleben ist monoton geworden, es mangelt in allen Lebensbereichen am ausschaffungsbedingt fehlenden Nachwuchs. Eine neue Initiative sieht deshalb vor, den Katalog der Straftaten probeweise auszusetzen

1 Das Durchdrückjahr. Einführung zum Lehrbuch der neuzeitlichen Schweizergeschichte für die Oberstufe. Marignano-Verlag; 2040. 